\title{
The great rise of Intestinal Research as an international journal 3 years after its language change to English as evidenced by journal metrics
}

\author{
Geum Hee Jeong ${ }^{1}$, Sun Huh ${ }^{2}$ \\ ${ }^{I}$ Division of Nursing and ${ }^{2}$ Department of Parasitology and Institute of Medical Education, Hallym University College of Medicine, Chuncheon, Korea
}

Intestinal Research was launched in 2003 by the Korean Association for the Study of Intestinal Diseases. In 2014, its language was changed to English only. It has been listed and searchable on PubMed Central since October 28, 2014. From January 2016, it became the official journal of the Asian Organization for Crohn's and Colitis. The journal received a letter of inclusion in Scopus, the largest citation literature database, from its Content Selection \& Advisory Board on August 5, 2016; consequently, the citation data and references of the journal are searchable from Scopus. These events reflect the rapid elevation from a Korean or English journal to an international journal. From this perspective, I would like to provide data that support the journal's elevation based on journal metrics, including the multinationality of authors and editorial board members, citation frequency, and Hirsch index.

The number of citable and noncitable articles per year, and the countries of origin of authors and editorial board members were obtained from the homepage of the journal (available from: http://www.irjournal.org/). The total citations per year were also obtained from Web of Science Core Collection. The impact factor was manually calculated, and the Hirsch index was analyzed from Web of Science Core

Received December 16, 2016. Revised December 17, 2016.

Accepted December 17, 2016.

Correspondence to Sun Huh, Department of Parasitology and Institute of

Medical Education, Hallym University College of Medicine, 1 Hallimdaehak-

gil, Chuncheon 24252, Korea. Tel: +82-33-248-2652, Fax: +82-33-241-

1672,E-mail: shuh@hallym.ac.kr

Financial support: This work was supported by the Hallym University

Research Fund (HRF-G-2015-4). Conflict of interest: None.
Collection. The impact factor reveals the citation details of articles published over the last 2 years; therefore, this metric indicates the speed with which a particular field of study has developed. A higher impact factor in a given field signifies rapid progress, leading to more frequent citation of recent articles. The impact factor was calculated using the following method, based on a previous report: ${ }^{1}$

Number of citable articles in 2014 and 2015: A

Number of citations of journal articles from 2014 and 2015 available in the database in 2016: B

Impact factor for $2016=\mathrm{B} / \mathrm{A}$

The Hirsch index is defined as "the number of papers with citation number $\geq h$ and it has index $h$ if $h$ of its $N_{p}$ papers have at least $h$ citations each and the other $\left(N_{p}-h\right)$ papers have $\leq h$ citations each." ${ }^{2}$ It was originally designed to measure the competency of researchers; however, it is now more widely used to measure the competency of journals or institutes. Frequently cited articles were classified by publication type and the counted or calculated data were presented as descriptive statistics.

The numbers of citable articles were 44,44 , and, 48 and that of noncitable articles were 18, 21, and 13 for the years 2014,2015 , and 2016, respectively. Of the 188 articles published between 2014 and 2016, 52 (27.7\%) were noncitable articles. The editorial board members are from 16 countries: six from Korea, four from Japan, three from China, two from Taiwan, two from India, two from the United States of America, and one each from the United Kingdom, Canada, Hong Kong, Malaysia, Singapore, Australia, Brazil, Belgium, Philippines, and Turkey. Authors were from six countries in 2014, 11 in 2015, and 10 in 2016. In this 3-year period, authors

\footnotetext{
(c) Copyright 2017. Korean Association for the Study of Intestinal Diseases. All rights reserved.

This is an Open Access article distributed under the terms of the Creative Commons Attribution Non-Commercial License (http://creativecommons.org/licenses/by-nc/4.0)

which permits unrestricted non-commercial use, distribution, and reproduction in any medium, provided the original work is properly cited.
} 
were from 13 countries (Fig. 1). The percentage of articles authored by Korean authors has steadily decreased from $91.9 \%$ ( 57 of 62 articles) in 2014, to $76.9 \%$ (51 of 65 articles) in 2015 , and $55.7 \%$ (34 of 61 articles) in 2016.

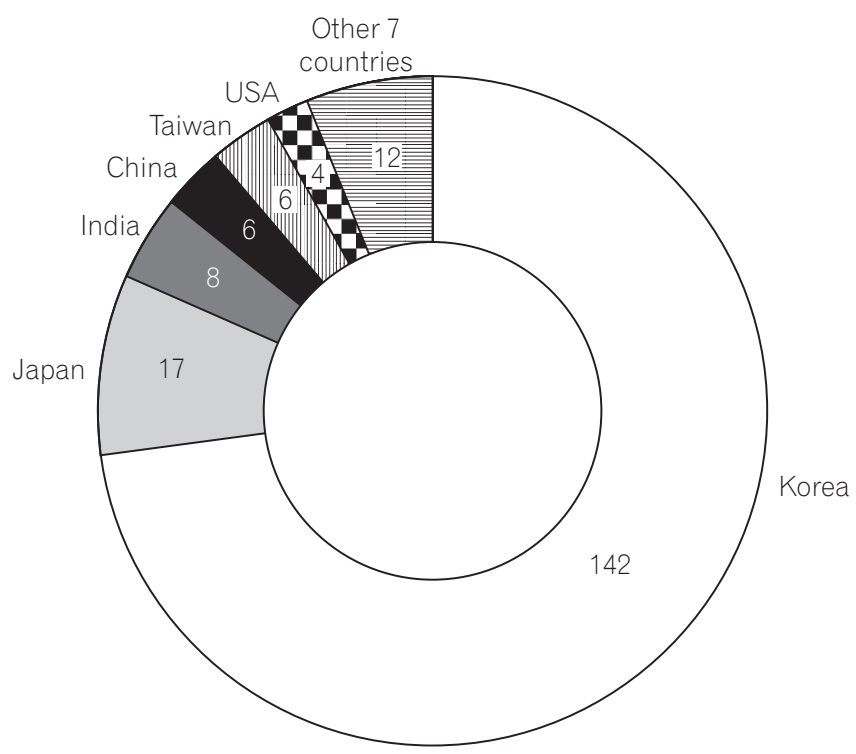

Fig. 1. Countries of authors' affiliation who contributed to Intestinal Research from 2014 to 2016. Available from: http://www.irjournal.org [cited 2016 Dec 15].
The impact factor for 2016, calculated using the formula mentioned previously, is $195 / 88=2.216$. Total number of citation to Intestinal Research was 403. Fig. 2 presents the number of citing articles taken from Web of Science Core Collection. The Hirsch index was 8 . Of the nine most frequently cited articles, six were of publication type "review" (Table 1).

An impact factor of 2.216 and 403 citations from Web of Science Core Collection were unexpected results for the

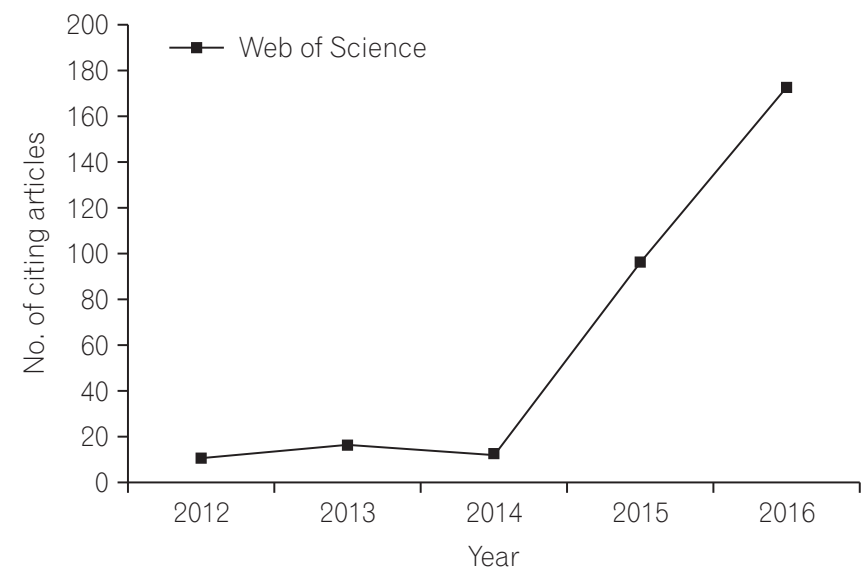

Fig. 2. Number of citing articles to Intestinal Research by year from Web of Science Core Collection. Available from: http://apps. webofknowledge.com [cited 2016 Dec 15].

Table 1. Most Frequently Cited Articles of Intestinal Research as Obtained from the Web of Science Core Collection and Their Publication Type

\begin{tabular}{|c|c|c|c|c|c|c|}
\hline No. & Title & Year & Volume & Page & $\begin{array}{l}\text { Times } \\
\text { cited }\end{array}$ & $\begin{array}{l}\text { Publication } \\
\text { type }\end{array}$ \\
\hline 1 & $\begin{array}{l}\text { Intestinal permeability regulation by tight junction: implication on } \\
\text { inflammatory bowel diseases }\end{array}$ & 2015 & 13 & 11 & 26 & Review \\
\hline 2 & Clinical application of genetics in management of colorectal cancer & 2014 & 12 & 184 & 22 & Review \\
\hline 3 & $\begin{array}{l}\text { Impact of sigmoidoscopy and colonoscopy on colorectal cancer incidence } \\
\text { and mortality: an evidence-based review of published prospective and } \\
\text { retrospective studies }\end{array}$ & 2014 & 12 & 268 & 16 & Review \\
\hline 4 & $\begin{array}{l}\text { The safety and efficacy of azathioprine and 6-mercaptopurine in the } \\
\text { treatment of Korean patients with Crohn's disease }\end{array}$ & 2009 & 7 & 22 & 11 & Original article \\
\hline 5 & $\begin{array}{l}\text { Inflammatory bowel disease-related colorectal cancer in the Asia-Pacific } \\
\text { region: past, present, and future }\end{array}$ & 2014 & 12 & 194 & 11 & Review \\
\hline 8 & $\begin{array}{l}\text { Clinical manifestations and course of intestinal Behçet's disease: an analysis in } \\
\text { relation to disease subtypes }\end{array}$ & 2005 & 3 & 48 & 8 & Original article \\
\hline 9 & $\begin{array}{l}\text { Clinicopathological characteristics of colon cancer diagnosed at primary } \\
\text { health care institutions }\end{array}$ & 2014 & 12 & 131 & 8 & Original article \\
\hline
\end{tabular}

${ }^{a}$ Available from: http://apps.webofknowledge.com [cited 2016 Dec 15]. 
period of 3 years after changing the language to English only (Fig. 2). The impact factor without journal self cites of 2.216 corresponds to the 2015 JCR ranking of 43 out of 79 SCIE journals in the category of gastroenterology and hepatology of which median value is 2.429. The impact factor for 2016 may yet show a consistent increase by April 2017, when the input of data is complete. The frequent citation may have been an effect of inclusion in PubMed Central like other medical journals from Korea. ${ }^{3}$ The platform of a literature database is important to gain exposure to world researchers and physicians. PubMed Central and PubMed are the most prominent platforms in the field of medicine because they not only provide free access to a large number of studies, 4.1 million and 26 million, respectively, but also have an excellent search function with controlled vocabulary. Therefore, based on journal metrics, the strategy of changing the language from 2014 was successful. Although the majority of authors had been from Korea, their numbers have decreased gradually (Fig. 1).

Additionally, the official publication of the regional society and the joint publication by East Asian countries also enabled a higher number of submissions to the journal from countries other than Korea. This could be a factor in the consistent increase in publication year on year. A multi-national editorial board also contributed to the multi-nationality of authors as they can submit their data or recommend Intestinal Research to colleagues.

The Hirsch index of 8 for the period of 3 years of publication in English is an excellent indicator of the journal's high performance (Table 1). In comparison with other journals, this value is very competitive. The Hirsch index of the Journal of Educational Evaluation for Health Professions was 5 for 10 years $^{4}$ and Archives of Plastic Surgery, 6 for 3 years. ${ }^{5}$ Reviews received a higher number of citations in this journal. This was the case with other journals ${ }^{4}$ although original articles were highly cited in some journals. ${ }^{6}$

In addition to journal metrics, the other factor unique to this journal is that it deals specifically with IBD. The other PubMed journals whose scope includes IBD are Journal of Crohn's \& Colitis published by Oxford University Press and Inflammatory Bowel Diseases published by Lippincott Williams \& Wilkins. Of the three, Intestinal Research is the only open access PubMed Central journal. Another advantage the journal offers is no submission fee from the author or article processing charge. Financial support provided by the publisher has been sufficient to maintain the journal's quantity and quality. The journal deals primarily with IBD of people from Asian countries. As the eating habits, meals, and immunological responses of people from Asian countries are different from North Americans and Europeans, the journal's scope is specialized to Asia.

The journal's reputation and brand value should be supported by not only high quality articles but also easy accessibility. ${ }^{7}$ For easy accessibility, transition to the English language is the first step. Subsequently, more information technology should be introduced in publishing. Then, introducing digital standards of scholarly journal publishing should be considered. The journal is already equipped with full text journal article tag suite extensible Markup Language (XML), CrossRef XML for digital object identifier, cited-by function, and reference hyperlink. For further progression, it is necessary to implement text and data mining, ORCID identifiers, and QR code on the journal homepage. ${ }^{8}$ Audio recording of the abstract or main text, ${ }^{9}$ audio presentations with slides, podcasts, ${ }^{10}$ and audio-visual presentation of the content are other tools that can attract readers and audiences. I also suggest uploading the full text JATS XML files to ScienceCentral (http://e-sciencecentral.org/) to enable automatic translation into 80 character languages and rapid search via Google Scholar.

In conclusion, the rise of Intestinal Research as an international journal and its inclusion in Scopus, 3 years after the language change, was possible due to the journal's excellent performance indicated through the journal metrics data, including the impact factor of 2.216; 403 citations in Web of Science; a Hirsch index of 8; and the multi-nationality of authors, who originated from 13 countries, and editorial board members, who originated from 16 countries. Adoption of the digital standard for scholarly journals will further enable the rapid growth of the journal's accessibility and reputation.

\section{REFERENCES}

1. Huh S. Promotion of the Journal of Exercise Rehabilitation to the international level based on journal metrics. J Exerc Rehabil 2016;12:510-514.

2. Hirsch JE. An index to quantify an individual's scientific research output. Proc Natl Acad Sci U S A 2005;102:16569-16572.

3. Jeong GH, Huh S. Increase in frequency of citation by SCIE journals of non-Medline journals after listing in an open access full-text database. Sci Ed 2014;1:24-26.

4. Huh S. How much is Journal of Educational Evaluation for Health Professions promoted based on journal metrics? J Educ Eval Health Prof 2015;12:57. 
5. Huh S. How journal metrics illustrate the transformation of archives of plastic surgery into an international journal. Arch Plast Surg 2014;41:617-619.

6. Huh S. Promotion of Neurointervention to international journal based on journal metrics. Neurointervention 2016;11:5-9.

7. Chi Y. Scientific publishing in the Asian century: an international perspective. Sci Ed 2016;3:112-115.

8. Jeong GH, Huh S. Status of digital standards in Korean medical journals in 2016. Sci Ed 2016;3:100-104.
9. Huh S. Revision of the instructions to authors to require a structured abstract, digital object identifier of each reference, and author's voice recording may increase journal access. J Educ Eval Health Prof 2013;10:3.

10. Schmidt HE. Scientific, technical, and medical podcasting in Korea. Sci Ed 2016;3:43-48. 